\title{
CULTURAL ADAPTATION AND VALIDATION OF THE METHOTREXATE INTOLERANCE SEVERITY SCORE (MISS) IN BRAZILIAN PORTUGUESE.
}

Jéssica Martins Amaral (Faculdade de Medicina da Universidade Federal de Minas Gerais, Belo Horizonte, MG, Brasil), Adriana Maria Kakehasi (Faculdade de Medicina da Universidade Federal de

Minas Gerais, Belo Horizonte, MG, Brasil), Maria José Menezes Brito (Escola de Enfermagem da Universidade Federal de Minas Gerais, Belo Horizonte, MG, Brasil)

\section{BACKGROUND}

Methotrexate (MTX) is an important medication in the treatment of rheumatoid arthritis (RA). Adverse events and gastrointestinal intolerance may limit its use and, therefore, its benefit. Methotrexate Intolerance Severity Score (MISS) questionnaire was developed for detection of MTX intolerance, allowing optimization or modification of treatment to prevent progression of RA. Thereby the objective of this work is to adapt and validate the MISS in Portuguese.

\section{MATERIALS AND METHODS}

The Portuguese version of the MISS was developed following the "Guidelines for the process of crosscultural adaptation of self-report measures". The new version has been tested on one hundred twenty patients with rheumatoid arthritis (2010 criteria or 1987 criteria). For the reliability assessment, the Cronbach's alpha coefficient was used for each factor. The Receiver Operator Characteristic (ROC) curve was constructed with the objective of finding the best cut-off point for this characteristic, weighing the sensitivity and specificity. The concordance among the results obtained was analyzed from the calculation of the Kappa coefficient and the factorial analysis with Varimax rotation.

\section{RESULTS}

This study developed and applied a culturally acceptable Portuguese version of the MISS. The MISS questionnaire presented internal consistency classified as "very good", since Cronbach's alpha is equal to 0.83 (95\% Cl: 0.79 to 0.87 ); there is no noticeable gain in Alpha after excluding any of the issues. Validation was demonstrated by the following parameters: the Kaiser-Meyer-Olkim sample adequacy test (KMO = $0.723)$ and the Bartlett's sphericity test $\left(\chi^{2}=499.98, p<0.001\right)$. It is observed that a factorial analysis with three factors is preferred, together since they account $57.9 \%$ of the variance of the results; the ROC curve of the MISS score considered the cut-off point at six points; sensitivity was $100 \%$ and specificity was $89.4 \%$.

\section{CONCLUSION}

This study demonstrated that the Brazilian version of the MISS is valid and reliable for the detection of MTX intolerance in patients with RA. 